\title{
Author Index Vol. 33, 1989
}

Aitkin, L.M. 325 Allison, J.D. 317

Altenmiiller, E. 141 Apicella\}P. 171,183

Barone.P. 132 Bass,A.H. 237 Beaubaton, D. 183 Behroozi,K. 175 Bessette, B.B. 268 Blum, B. 61, 104 Bonnet, M. 147 Buettner, U.W. 75

Camarda,R. 118 CoeiTelC. 80

Dodson.D.L. 261 Droulez,J. 85

Erichsen, J.T. 268 Evinger, C. 268

Favilla.M. 69 Fischer, B. 61,109 Flash, T. 63 Fogassi, L. 118

Freund,H.-J. 136 
Fukushima, J. 356 Fukushima, K. 356

Gentiluc\&i, M. 118 Ghez,C. 69 Gilhodes, J.-C 165 Gisbergen, J.A.M. van 90 Glass, I. 95 Godschalk.M. 122

Hadani,I. 99 Heffner, E.H. 248

Heffner,R.S. 248 Hening,W. 69 Hodos.W. 268

Jacobs, A.M. 80 tfaffi> Je 25 Joseph, J.P. 132 Jung,R. 141

Karli,P. 153, 162 Kase,M. 356 Knigge,K.M. 193 Koehler,W. 75

Landwehrmeyer, B. 141 Larson, C.F. 261 
LeMoal.M. 157 Lemon, R.N. 122 LeVy-Schoen, A. 80 Louilot,A. 157 Luppino, G. 118

Mac Kay, W. A. 147 Matelli,M. 118 Mayner, L. 293, 303,342 Melrose, P.A. 193

Najenson, T. 175 BeSofflR§. 325 ^lsmxawa, K. 15

Ohashi,T. 3^| Opstal, A.J. van 90

Orpaz,D. 179

Passingham, R.E. 189 Pause, M. 136 Perez, E. 25 Pettigrew, J.D. 279 Phillips, S.J. 268 Pritz,M.B. 1

Rizzolatti, G. 118

Roll,J.-P. 165

Ron,S. 85,95,175,179 
Schmid,R. 179 Schmitt,P. 162

Schwartz, K. 95 Seal, J. 113 Simon, H. 157 Stritzel, M.E. 1 Suzuki, Y. 356

Taghzouti,K. 157 Tardy-Gervet, M.-F. 165 Thier.P. 75 Trouche,E. 171, 183

Umetani,T. 334

Vaadia,E. 127

Vardi,N. 99 Viallet,F. 183 Vieville,T. 85 Vischer,H.A. 205,223

Ward, J.P. 261 Wassersug,R. 15 Wathey,J.C. 279 Webb,J.F. 34 Wilczynski, W. 317 Winker, T. 141 